\title{
Market Efficiency Reloaded: Why Insider Trades do not Reveal Exploitable Information
}

\begin{abstract}
Insider trading studies related to the German market have emphasized that outside investors may earn excess returns by mimicking the transactions of corporate directors. Such a result, provided that it holds, would constitute a serious violation of the efficient market hypothesis. The results presented in this paper, though, show that this anomaly is mainly caused by a subset of stocks with high arbitrage risk as measured by their idiosyncratic volatility. This restrains arbitrageurs from engaging in otherwise profitable and price-correcting trades. As arbitrage risk is positively related to a stock's bid/ask-spread, we show that the information conveyed by insider trades cannot be exploited in terms of generating abnormal returns once these transaction costs are taken into account. We conclude that the market's under-reaction to reported insider trades can mainly be explained by the cost associated with risky arbitrage. Our findings provide evidence that the German stock market is efficient with respect to insider trades in the sense that prices reflect publicly available information to the point where the marginal benefit of acting on information exceeds marginal costs.
\end{abstract}

JEL Classification: G11, G14

Keywords: Insider Trading, Directors' Dealings, Arbitrage Risk, Market Efficiency 


\section{Introduction}

According to well documented empirical evidence company insiders exploit their informational advantage when trading in their own company's stocks. ${ }^{1}$ While it is not surprising that insiders benefit from their informational advantage, it would be against the notion of efficient capital markets if outsiders by mimicking published insider transactions could earn excess returns as well. In fact, evidence related to common-law countries is, roughly spoken, in accordance with this view of informational efficient markets. ${ }^{2}$

Pertinent empirical research with respect to code-law countries only recently emerged, as mandatory disclosure of insider trades has not yet a long history. For instance, reporting of insider trades is mandatory in Germany since 2002. Interestingly, first evidence collected for the German market indicates that arbitrage opportunities may exist for outsiders mimicking published insider transactions. According to Stotz (2006) the average abnormal return net of transaction costs over a 25-day-window following the announcement of a purchase is equal to a statistically significant $1.81 \%$. In addition, it seems that excess returns accumulate slowly after the reporting of insider trades. For example, Betzer and Theissen (2007b) report average abnormal returns of $1.70 \%$ resp. $2.88 \%$ for purchases resp. sales in the first ten days following the announcement. Another ten days later, excess returns accumulate to $3.57 \%$ resp. $3.40 \%$. These findings suggest that the market adjusts relatively slowly to the information conveyed by insider trades. In efficient markets, however, prices supposedly jump immediately to their new equilibrium level after the release of new information. If this is not the case, arbitrage opportunities may arise.

In this paper we investigate why sophisticated investors, such as hedge funds and other institutional investors, do not eliminate this alleged inefficiency by

\footnotetext{
${ }^{1}$ Chang and Suk (1998), Jeng et al. (2003) and others report such results for the US. For the UK, Fidrmuc et al. (2006) document similar and more pronounced findings. First empirical and corresponding evidence for Germany exists, for example, from Betzer and Theissen (2007b).

${ }^{2}$ Cf. Seyhun (1986) and Rozeff and Zaman (1988) for the US, or Friederich et al. (2002) for the UK. However, for the US Bettis et al. (1997) argue that arbitrage opportunities may arise.
} 
locking in arbitrage profits. Although we agree on the findings reported above, we show that they do not witness any breach of the efficient market hypothesis. In fact, we hypothesize that arbitrage risk, as measured by the level of idiosyncratic risk, makes arbitrage costly and hereby prevents investors from exploiting seemingly profitable post-event abnormal returns. As a corollary, we hypothesize that arbitrage risk is negatively related to the speed of price adjustment after reported corporate dealings.

These findings extend a recently evolved strand of literature, in which it is pointed out that some alleged market anomalies can perfectly be explained once the role of idiosyncratic risk in arbitrage strategies is understood. ${ }^{3}$ Mashruwala et al. (2006), for example, show that the so-called accrual anomaly is concentrated in stocks with high idiosyncratic risk. Mendenhall (2004) reports similar results for the post-earnings announcement drift and Wurgler and Zhuravskaya (2002) for the index effect. Similarly, Pontiff (1996) argues that closed-end fund's mispricing may be caused by arbitrage risk and Ali et al. (2003) show that the well-known book-to-market effect is related to idiosyncratic risk. ${ }^{4}$. In the context of director's dealings Ben-David and Roulstone (2007) show that the returns to insiders are positively related to the level of arbitrage risk.

We extend this line of research and make two distinct contributions to the existing literature. First, this paper extends the findings of Ben-David and Roulstone (2007) by exploring the relationship between arbitrage risk and abnormal returns to outsiders mimicking published insider transactions. Second, we scrutinize the relationship between idiosyncratic risk and transaction costs. As arbitrage risk is supposed to increase transaction costs we hypothesize that an appropriately defined arbitrage strategy generates lower returns than it is suggested by looking at abnormal returns only. As a corollary, we examine several other potential determinants of returns to directors' dealings that have previously been neglected. In particular, we control for the opportunity cost of

\footnotetext{
${ }^{3}$ For an overview on this line of argument cf. Schwert ().

${ }^{4}$ For a more extensive overview on this specific strand of the literature cf. Pontiff (2006), p. $45 \mathrm{n}$.
} 
capital, direct and indirect transaction costs, and financial distress.

Similarly to existing research, we report abnormal returns of $1.46 \%(-1.87 \%)$ and $1.99 \%(-3.12 \%)$ in the 10 and 20 days after the reporting of insider purchases (sales), respectively. While our results confirm the existence of large and statistically significant post-announcement abnormal returns, we also demonstrate that outsiders will hardly be able to profit from mimicking insider trades. By sorting insider trades in relation to their level of arbitrage risk, we show that large abnormal returns cluster in highly idiosyncratic stocks. Our cross-sectional regression approach confirms that idiosyncratic risk is positively and robustly related to excess returns. Furthermore, we develop a simple arbitrage trading strategy and find that the presence of arbitrage risk renders it unprofitable.

The remaining paper is structured as follows. Section 2 summarizes the institutional background of directors' dealings in Germany and gives a brief overview of the existing literature . Section 3 describes the data set, and section 4 discusses the research design and results. Section 5 concludes.

\section{Institutional Background and Literature}

According to $\S 15$ a of the Security Trading Act (Wertpapierhandelsgesetz), insiders have to report all trades to Germany's financial services authority(BaFin), and to the company itself within five business days. ${ }^{5}$ The law defines company insiders as members of the executive and supervisory boards as well as the respective spouses, relatives of first-degree, and legal entities owned or controlled by company insiders. Other employees have no obligation to report as long as they have no managerial function. In contrast to the US and UK, major shareholders and former directors are exempted from the reporting obligation. Furthermore, insiders may refrain from reporting their trades if the cumulative

\footnotetext{
${ }^{5}$ This ruling became effective on July 1, 2002. Prior to the Anlegerschutzverbesserungsgesetz (AnSVG), which became effective on October 30, 2004, trades had to be reported without delay. This vague definition caused long reporting delays and was therefore replaced.
} 
trading volume does not exceed 5,000 euros in one calendar year. ${ }^{6}$

To the best of our knowledge, eight studies have been conducted on directors' dealings in Germany. Rau (2004), Heidorn et al. (2004) and Stotz (2006) examine the market's reaction to insider transactions. Tebroke and Wollin (2005) study the determinants of abnormal returns such as firm size and the transaction volume of insider trades. Betzer and Theissen (2007b) extend this line of research by controlling for the firm's ownership structure. Klinge et al. (2005) take event clustering into account and use non-overlapping observations. Dymke and Walter (2006) investigate the exploitation of private information by insiders, and Betzer and Theissen (2007a) research the relationship between excess returns and reporting delay.

All studies agree that post-announcement price effects of insider trades are statistically significant and more pronounced in Germany than in the US. In addition, abnormal returns accumulate over time. At a first glance, these findings are not in accordance with the existence of an informational efficient capital market. Although we corroborate these findings, it is the main contribution of this paper to show that this effect is not exploitable because of the existence of transaction costs and, more generally, arbitrage risk.

Of course, mispriced securities offer market participants the opportunity to earn risk-free profits by engaging in arbitrage trades. An arbitrage trade in its original sense entails going long (short) in an underpriced (overpriced) asset and short (long) in a perfect substitute to hedge against changes in fundamental value. No net investment is required, and profits are earned once the mispricing disappears. Arbitrage is, however, not as straightforward as the outlined trading strategy suggests. In practice, arbitrage is costly because arbitrageurs incur transaction and holding costs.

Holding costs accumulate over time and are proportionate to the investment horizon. They include the opportunity cost of capital and costs arising out of shorting an asset. Besides short-selling constraints that make shorting risky,

\footnotetext{
${ }^{6}$ Prior to the AnSVG, trades were exempt from the reporting obligation if the cumulated trading volume did not surpass 25,000 euros in 30 days.
} 
arbitrageurs may not receive full interest on short-sale proceeds. ${ }^{7}$ More importantly, holding costs include arbitrage risk, which arises out of imperfectly hedging the fundamental risk associated with the mispriced security.

It is widely accepted that arbitrage risk is the most important cost traders face. $^{8}$ If arbitrageurs can perfectly hedge a mispriced security's fundamental value, the mispricing will disseminate over time, resulting in a risk-free profit. If, however, few good substitutes exist and the hedge is imperfect, arbitrageurs will be subject to idiosyncratic risk. As a result, traders will also suffer from mispricing risk as the mispricing might strengthen further in the short-term before the security's price converges to its fair value (Shleifer and Vishny 1997). This may force the arbitrageur to prematurely unwind the trading position and incur a loss (Tuckman and Vila 1992). Thus, the riskiness of an arbitrage trade ultimately depends on the quality of the hedge, which in turn is only as good as the available substitutes.

The availability of close substitutes is largely determined by the level of idiosyncratic risk associated with a security. This may seem counter-intuitive because the CAPM implies that idiosyncratic risk does not matter because of diversification. The systematic part of a stock's total risk, however, can be hedged relatively easily by taking an opposite position in, for example, the market index. It is, however, substantially more difficult to find a hedging position if a stock is highly idiosyncratic. Even if arbitrageurs have many projects available that allow diversification, idiosyncratic risk still matters (Pontiff 2006). Thus, arbitrageurs may be less inclined to engage in price-correcting trades if the mispricing occurs in a highly idiosyncratic stock.

Knowing that prices will deviate more strongly from their fair value if idiosyncratic risk is high, we turn to the question of how arbitrage risk affects the behavior of outsiders trying to mimic directors' dealings. In essence, directors'

\footnotetext{
${ }^{7}$ Short-selling constraints include various costs and risks of shorting, as well as legal and institutional restrictions. For example, traders may find it difficult to find a counterpart willing to lend shares to the short seller. In addition, lenders may recall their stock at any time. If the borrower is unable to find another lender, the borrower may be forced to close his position.

${ }^{8}$ For a detailed review of the arbitrage risk literature, see Pontiff (2006).
} 
dealings can be interpreted as public mispricing signals. Disregarding liquidity needs, portfolio rebalancing considerations, and deliberate signalling, rational insiders will only buy (sell) stocks in their own companies if they believe it to be undervalued (overvalued), since insiders put their own wealth at stake. ${ }^{9}$

If, however, a stock's idiosyncratic volatility is high, outsiders will be less inclined to engage in price-correcting arbitrage trades. As a result, prices will not immediately converge to their new equilibrium level after the announcement of insider transactions as suggested by the efficient market hypothesis (Fama 1970). Instead, the market will incorporate the information conveyed by insider trading signals slowly into security prices and compounded abnormal returns will increase as longer time periods are considered.

The above discussion does not imply that arbitrage risk eliminates all arbitrage trading activity after reported insider trades in highly idiosyncratic stocks. Pontiff (2006) argues that rational investors will engage in arbitrage trades until the cost of doing so equals the benefits. Thus, our results do not support the notion of a strongly efficient German capital market but satisfy a more sensible version of market efficiency that says that prices reflect information to the point where the marginal benefit of acting on information does not exceed marginal costs (Jensen 1978).

\section{Data}

\subsection{Data Set}

We obtain data from BaFin, Thompson Financial Datastream and Worldscope.

Dividend adjusted daily closing prices, bid/ask quotations and unadjusted prices are collected from Datastream. As recommended by Ince and Porter (2006), we carefully screen the data and delete zero returns from dead stocks. In addition, we delete price observation of non trading days and calculate arith-

\footnotetext{
${ }^{9}$ From the perspective of the insider, a company's over- or undervaluation may arise because of weak arbitrage forces, i.e., the stock is highly idiosyncratic, or because of their private information (Ben-David and Roulstone 2007).
} 
metic returns. We also use Datastream to obtain trading volume figures and the daily 3-month EURIBOR rate. Moreover, we collect several accounting data items, such as the market-to-book ratio and interest coverage figures, from Worldscope.

Data on directors' dealings is obtained from BaFin, which maintains a publicly accessible database. Our study includes all trades reported between July 1, 2002 and October 31, 2007. For this time period, the database contains a total of 18,619 entries. The available data items include, amongst others, the date of the trade as well as the date of reporting, the full name of the insider, the company, the name and local security code of the traded security, the number of shares traded, the share price, the position of the insider, and the type of transaction. ${ }^{10}$

Since German law requires insiders to report all trades in stock, bonds, and other company-related rights, the database also includes option exercises, transactions in derivatives and convertible bonds, and stock allocations due to capital increases. Furthermore, some trades do not lead to a change in the number of stocks held by an insider, for instance a purchase and sale transaction on the same day of equal size, or trading among related insiders, such as a stock transfer to the spouse. We attribute to these transactions no or only limited informational value and, therefore, delete them from our sample.

In addition, we delete all trades in non German securities. We also discard trades with a transaction size of 1,000 euros or less, since these may be disregarded by the market. In some instances, trades are reported on a weekend or holiday. In these cases, the announcement day is set to the next following business day.

Although reporting delays, the number of days between the date of reporting and the date of the actual trade, should in theory not exceed 5 business days, delays can be substantial. Because transactions with extremely long reporting

\footnotetext{
${ }^{10}$ We perform various consistency checks utilizing other sources of directors' dealings such as insiderdaten.de, $2 \mathrm{iQ}$ Research, and company websites to verify the integrity of our data set.
} 
delays could distort our results, we drop all trades with a delay of more than 30 business days from our sample.

Very often, several trades that were executed on different dates are reported on the same day. Moreover, different insiders from the same company can report trades on the same day. We aggregate such trades for each company along the reporting day dimension. The trading volume and transaction type are recalculated accordingly. ${ }^{11}$ Again, trades with an aggregated transaction volume of less than 1,000 euros are discarded. Because we include the reporting delay as a variable in our cross-sectional regression analysis, we set the trading day to the most recent trading date of the transactions being aggregated.

After these data adjustments, 5,128 transactions (2,782 purchases and 2,346 sales) remain in the sample for the event study analysis in section 4.2. Because of data unavailability for several of our independent regression variables, the cross-sectional analysis sample in section 4.4 consists out of 4,796 transactions (2,611 purchases and 2,185 sales).

\subsection{Construction of Variables}

The independet variables used in section 4.4 can be categorized into five (not mutually exclusive) groups: holding costs, transaction costs and trade-, insiderand company-specific variables. The definition of the variables is summarized in Table 1. In the following we restrict our comments to those variables which are crucial to our analysis and deserve additional explanation.

As outlined in section ??, arbitrage risk stems from imperfect hedging. We follow Pontiff (1996) and Wurgler and Zhuravskaya (2002) in using a stock's idiosyncratic risk as an empirical proxy for arbitrage risk. The theoretically more vested alternative would be to measure a firm's arbitrage risk as the residual variance from a regression of stock returns on the returns of a close substitute or a basket of close substitutes. Wurgler and Zhuravskaya (2002), however, show

\footnotetext{
${ }^{11}$ The transaction volume is summed over the respective trades with a negative sign in the case of sales. If the aggregated volume is greater (smaller) than zero, the transaction type is set equal to an insider purchase (sale).
} 
that both measures of arbitrage risk are highly correlated (0.98) and yield very similar results.

Therefore, we construct our proxy for arbitrage risk (IRISK) as the residual variance of a market model regression of stock returns on market returns. In particular, we regress the returns of the days $t_{-261}$ to $t_{-21}$ relative to the reporting day of the insider transaction $t_{0}$ against the CDAX performance index. Our results are robust to different lengths of the return windows used to estimate $I R I S K .^{12}$

Because the distribution of IRISK has a high positive skewness and kurtosis, we take the natural logarithm and include the variable IRISKLOG in our regression analysis. In addition, we center IRISKLOG on zero to ease the interpretation of our results. Again, our findings are robust to the inclusion of either IRISK or IRISKLOG. Since we hypothesize that large abnormal returns after directors' dealings are concentrated in highly idiosyncratic stocks, we expect the coefficient of IRISKLOG to be positive.

We also include systematic risk (SYSRSK), which is the part of the volatility of stock returns that can be hedged relatively easily, in our analysis. We compute $S Y S R S K$ as the total variance of stock returns minus the variance of the residuals $(I R I S K)$. For the same reasons as above, we take the natural logarithm of $S Y S R S K$ and center the variable on zero (SYSRSKLOG). This also allows a direct comparison of the coefficients of arbitrage risk and systematic risk.

In practice, systematic risk should also matter to arbitrageurs, although less so than idiosyncratic risk (Shleifer and Vishny 1997). Therefore, we expect a positive relationship between SYSRSKLOG and the dependent CAR variable, but one that is less pronounced than that between excess returns and IRISK.

Following Pontiff (1996) we also use interest rates as a holding cost item. Specifically, we include the 3-month EURIBOR measured one day prior to the

\footnotetext{
${ }^{12}$ We also compute IRISK with shorter return windows comprising 90 and 180 days. Our cross-sectional results, however, prove to be insensitive to these alternative measures of $I R I S K$.
} 
reporting date as proxy for the risk-free rate.

Most empirical studies on director's dealings ignore transaction costs such as commissions, bid-ask spreads, or illiquidity. Bhushan (1994) and Bhardwaj and Brooks (1992) demonstrate that direct transaction costs such as commissions and bid-ask spreads are inversely related to share price. Thus, we include $S P R I C E$, the average (unadjusted) stock price over the days $t_{-121}$ to $t_{-21}$ in our analysis as a transaction cost item.

Illiquidity in stocks can lead to delays in the processing of orders, which can cause adverse price effects. Therefore, illiquidity poses an indirect transaction cost that is captured by the variable VOLUME (Admati and Pfleiderer 1988; Bhushan 1991). VOLUME is defined as the mean euro trading volume of a company's stock over the days $t_{-121}$ to $t_{-21}$. The trading volume data is derived by aggregating the volume of all German stock exchanges on which the respective stock is traded. We expect $S P R I C E$ to be positively and VOLUME to be negatively related to post-event CARs.

Additionally, we use several control variables related to the characteristics of insider trades, which are well known from the literature. It should just be mentioned, the we use the indicator variable INSALE to account for any differences in the explanatory power of insider purchases and sales. This differential effect has been documented in Seyhun (1986) and Fidrmuc et al. (2006). According to their research, INSALE is set to one for sale transactions and is expected to be negatively related to absolute CARs. As additional control variables we use relative trade size TRADSZ (expected to have a positive influence), reporting delay $D E L A Y$ (expected to have a negative influence) and a stock's past performance ${ }^{13}$ PASTRET (expected to have a negative influence). For the definition of these variables see Table 1 .

It might be expected that the quality of information conveyed by a transaction depends on the type of insider who trades (Seyhun 1986). Supposedly,

\footnotetext{
${ }^{13}$ Rozeff and Zaman (1998) demonstrate that abnormal returns after directors' dealings are negatively related with past returns and conclude that insiders follow a well-informed contrarian approach to investing.
} 
members of the executive board possess information superior to that available to members of the supervisory board or the management. Thus, trades by executives should trigger larger price effects. On the other hand, Jeng et al. (2003) propose that better-informed insiders such as CEOs refrain from exploiting their comparative advantage because they find themselves subject to increased scrutiny from regulators and the public.

We capture the effect of an insider's position on abnormal returns with a set of three dummy variables for members of the executive board POSEB, the supervisory board POSSB, and the management POSMNG. Transactions executed by other insiders are the base case. If different groups of insiders report their trades on the same day, we set the dummy variable of the presumably best informed group to one and the others to zero.

Although we expect the coefficients of the dummy variables to be positive, it is difficult to predict their relationships to each other in terms of significance and size.

Finally, as company specific control variables we use firm size ${ }^{14}$ as measured by the market value of equity $M V$ or its (centered) natural logarithm $M V L O G$ (expected to have a negative influence) and market-to-book ratios $M T B V \cdot .^{15}$ Again, for the specific definition of these variables see Table 1 .

As an additional firm specific variable we use financial distress as firms in poor financial conditions may react more sensitively to insider trading signals than stocks of healthy companies (Fidrmuc et al. 2006). Purchases in poorly performing firms may indicate that insiders, who supposedly possess superior information, believe that a company turnaround is possible and vice versa. We construct a dummy variable, DISTRS, to examine the relationship between returns to directors' dealings and financial distress. The dummy variable is set to one if the company's interest coverage ratio is below one in the two consecutive years prior to the reporting date. We define the interest coverage

\footnotetext{
${ }^{14}$ Firm size could also pick up transaction cost effects. Schultz (1983) and Stoll and Whaley (1983), for example, show that there is a negative monotonic relationship between firm size and the bid-ask spread.

${ }^{15}$ We exclude any observations where $M T B V$ is negative, zero, or greater than 15 .
} 
ratio as a firm's earnings before interest and taxes (Ebit) divided by its interest expenses. ${ }^{16}$ We expect a positive relationship between our proxy for financial distress and CARs.

Finally, it should be noted that Fidrmuc et al. (2006) and Betzer and Theissen (2007b) show that a company's ownership structure also influences abnormal returns to reported insider trades. However, we do not integrate ownership variables in our analysis as this paper is mainly focused on the impact of arbitrage risk.

\subsection{Descriptive Statistics}

Table 2 contains summary statistics for the cross-sectional regression sample consisting of a total of 4,796 observations. For completeness, we also provide a breakdown of statistics for purchases and sales only. Our (unlogged) proxy variable for arbitrage risk, IRISK, has a mean value of 0.0012 . At 0.0001 , the average systematic risk is considerably smaller. This is consistent with the notion that a stock's total volatility is primarily determined by its level of idiosyncratic risk. The average relative trade size is at $1.375 \%$ markedly higher for sales than for purchases at $0.45 \%$. Our sample also displays significant differences between sales and purchases in the case of past returns. Medium (market adjusted) abnormal returns prior to purchases is $-0.51 \%$ and $-8.49 \%$ for purchases. $52.7 \%$ of the reported trades involved transactions by members of the executive board. The average firm in our sample has a market value of common equity of 2,926 million euros and a market-to-book ratio of 2.56. A relatively large proportion of insider trades, $11.41 \%$, take place in financially distressed firms.

Table 3 displays the correlation coefficients of selected variables. ${ }^{17}$ Idiosyn-

\footnotetext{
${ }^{16}$ Theory suggests the use of earnings before interest, taxes, depreciation, and amortization (Ebitda) instead of Ebit. Rajan and Zingales (1995), however, document that the two measures are highly correlated. Furthermore, Jostarndt (2006) argues that the use of Ebit as the nominator is more appropriate for the German market because in recent years many firms have defaulted as a result of unexpectedly high depreciations of goodwill.

${ }^{17}$ With one exception (VOLUME-MVLOG) correlation coefficients do not indicate any problem of multicollinearity. The variance inflaction factors (VIFs) reported in the regression analysis, however, are in any case below 5 . Hence, multicollinearity should not be an issue.
} 
cratic risk is negatively correlated with firm size and stock trading volume, which could imply that arbitrage risk clusters in small and thinly traded stocks.

\section{Empirical Analysis}

\subsection{Methodology}

We use the market model to compute cumulative (average) abnormal returns. ${ }^{18}$ Our event window is composed of 41 days centered on the event date $t_{0}$, which is defined as the announcement day of insider transactions.

For each security i in our sample, the unexpected or abnormal component of return on day $t$ is given by

$$
\widetilde{A R}_{i, t}=\widetilde{R}_{i, t}-E\left(\widetilde{R}_{i, t}\right)
$$

where $E\left(\widetilde{R}_{i, t}\right)$ is the expected or predicted return and $\widetilde{R}_{i, t}$ is the observed or actual return. ${ }^{19}$

Under the market model, the expected return is given by

$$
E(\widetilde{R})_{i, t}=\alpha_{i}+\beta_{i} \widetilde{R}_{m, t}
$$

where $\widetilde{R}_{m, t}$ is the return of the market portfolio on day $t$. We use the CDAX, a broad and value-weighted German performance index, as a proxy for the market portfolio.

To obtain the parameters $\alpha$ and $\beta$, we run an ordinary least squares regression (OLS). In particular, we regress $\widetilde{R}_{i, t}$ on $\widetilde{R}_{m, t}$ during the estimation period, which ranges from $t_{-201}$ to $t_{-21}$.

To test the null hypothesis that CAARs are normal, securities are aggregated in the cross-section and across time. For $\mathrm{N}$ securities, the cross-sectional average

\footnotetext{
${ }^{18}$ We follow the framework proposed by Campbell et al. (1997) and MacKinlay (1997).

${ }^{19}$ We generally employe arithmetic returns for all of our return measures. As Dissanaike and Le Fur (2003) point out, logarithmic returns may not be well specified if a study's aim is to test whether events are persistently associated with excess returns.
} 
abnormal return for day $t$ is:

$$
\widetilde{A A R_{t}}=\frac{1}{N} \sum_{i=1}^{N} \widetilde{A R}_{i, t}
$$

To examine return windows extending over multiple days, we compute several CAAR measures:

$$
\widetilde{C A A} R\left(t_{1}, t_{2}\right)=\sum_{t=t_{1}}^{t_{2}} \widetilde{A A R_{t}}
$$

To test the null hypothesis of no abnormal returns, we use a standard test statistic given by

$$
t_{C A A R}: \frac{\widetilde{C A A} R\left(t_{1}, t_{2}\right)}{\sqrt{\sigma_{C A A R}^{2}\left(t_{1}, t_{2}\right)}}
$$

where

$$
\sigma_{C A A R}^{2}\left(t_{1}, t_{2}\right)=\left(t_{2}-t_{1}\right) \sigma_{A A R}^{2}(t)
$$

and $\sigma_{A A R}^{2}(t)$ is the variance of the average abnormal return on day $t$.

Although the above test statistic is well specified if the variance of average abnormal returns is estimated correctly, event-time clustering renders the underlying independence assumption for abnormal returns in the cross-section invalid (Collins and Dent 1984 and Bernard 1987). To address this issue, we also compute the non-parametric rank test proposed by Corrado (1989), which is robust in the presence of non-normality, infrequent trading, and event-induced variance (Campbell and Wesley 1993).

To further address the issue of event-time clustering, we construct a second sample that contains only trades of companies with no other trades in the time window ranging from $t_{-10}$ to $t_{+10}$. This control sample is about half the size of the unadjusted data set and consists of a total of 1,688 transactions (828 purchases and 860 sales). Our results are not substantially altered by this adjustment and, therefore, subsequently not reported. 


\subsection{Event Study Analysis}

Results of the event study analysis are reported in table 4 . While we concentrate on post-event CAARs in the subsequent analysis, we also report pre-event excess returns to facilitate comparability with previous studies. Figures 1 and 2 depict abnormal returns over time.

Pre-event abnormal returns from $t_{-20}$ to $t_{-1}$ accumulate to $-2.51 \%(1.95 \%)$ for purchases (sales) compared to a post-event CAAR $(0 ; 20)$ of $1.99 \%(-3.12 \%)$. This inverse relationship confirms the results of previous studies that insiders are able to time their transactions well and decide to trade after a period of significant abnormal returns.

Overall, abnormal returns are more pronounced around sales than purchases. This includes pre- and post-event CAARs. Compared to purchases, sales require a period of greater positive abnormal returns to prompt insider transactions. In addition, the market seems to react more strongly to the announcement of insider sales. Although studies for the US and UK stock markets have consistently found greater abnormal returns to purchases than to sales, this result confirms the findings of previous studies for the German market. Rau (2004), Betzer and Theissen (2007b) and Klinge et al. (2005) all find the market's reaction to be more pronounced to sales than to purchases, at least over longer event windows.

On the event day the market reacts in the expected direction. $\operatorname{CAAR}(0)$ amounts to $0.22 \%$ (significant) for purchase and $-0.10 \%$ (not significant) for sale transactions. ${ }^{20}$ In relationship to $\operatorname{CAAR}(0 ; 10)$ and $\operatorname{CAAR}(0 ; 20)$, however, the market's immediate reaction to reported insider trades on the event date $t_{0}$ is relatively small. At a first glance, this suggests that the price discovery after the announcement of corporate dealings is inefficient and slow, which should open up the opportunity for outsiders to profit from reported insider trades. In fact, the academic as well as the practitioner oriented literature is pointing in this direction. In this paper, however, we argue that these results may be in

\footnotetext{
${ }^{20}$ In unreported results, CAARs also remain significant if the event date is set to one day after the reporting day.
} 
accordance with the view of an information efficient market as it is not clear whether this price adjustment patterns can really be exploited by outside investors. Therefore, in the remaining part of the paper we will first show that observed abnormal returns are clustered among stocks with high arbitrage risk and second that this effect cannot be exploited once transaction costs are taken into account.

\subsection{CAARs for Arbitrage Risk Portfolios}

This section analyzes CAARs for different levels of arbitrage risk by sorting trades into quantiles according to the level of idiosyncratic risk of the underlying stock. This procedure is repeated for all trades and for purchases and sales only. Quantile 1 contains trades associated with lowest arbitrage risk and quantile 5 contains trades with highest arbitrage risk as measured by our proxy variable IRISK. In addition, we compare the CAARs of both quantiles by the means of a one-sided test of difference in means. Results are reported in table 5.

Excess returns after directors' dealings prove to be highly sensitive to the level of arbitrage risk. The difference in CAARs is in all instances highly significant at the $1 \%$ level and ranges in the pooled sample from $1.77 \%$ for $\operatorname{CAAR}(0 ; 5)$ to $4.90 \%$ for $\operatorname{CAAR}(0 ; 20)$. The greatest difference can be observed for sales with a spread of $6.09 \%$ in CAAR $(0 ; 20)$. In general, the difference in returns is larger for sales than for purchases. This implies a stronger relationship between arbitrage risk and excess returns in the case of sales than in purchases. This finding will be confirmed in the cross-sectional regression analysis in section 4.4.

In addition, our results demonstrate that returns accumulate over time in highly idiosyncratic stocks but remain more or less constant if arbitrage risk is low. In fact, $\operatorname{CAAR}(0 ; 20)$ is smaller than $\operatorname{CAAR}(0 ; 10)$ in the low arbitrage risk purchases sample. These findings are consistent with the notion that prices adjust slowly if arbitrage forces are weak because of high idiosyncratic risk. If arbitrage risk is low, on the other hand, prices adjust quickly to their new equilibrium level and subsequently follow a random walk. 


\subsection{Cross-sectional Regression Analysis}

This section examines the relationship between arbitrage risk and returns to reported insider trades by means of a cross-sectional regression. Because of higher explanatory power as indicated by adjusted $R^{2}$, we focus on $\operatorname{CAR}(0 ; 10)$ and $\operatorname{CAR}(0 ; 20)$ as dependent variables. For both CAR variables, we run a pooled regression as well as one for purchases and sales only. To accommodate the interpretation of our results, abnormal returns after sales are multiplied by minus one. Thus, coefficients should be of the same sign regardless of the examined regression model. As outlined in the discussion of variables in section 3.2 , the analysis includes proxies for holding and transaction costs as well as trade-, insider- and company-specific variables. A summary of the independent regression variables can be found in table 1. Regression results are reported in table 6 .

In support of our previous results, we find that arbitrage risk is strongly and positively related with post-event CARs. IRISKLOG is significant in all regression models at the 5\%-level at least. Moreover, arbitrage risk has a substantial effect on post-event CARs as indicated by its regression coefficient. Furthermore, we can induce from the regression results that the relevance of arbitrage risk strengthens as longer event windows are being considered. Tstatistics as well as regression coefficients increase with time. This is consistent with arbitrage risk being a form of holding cost that is proportional to the investment horizon (Pontiff and Schill 2003).

Regarding the effect of systematic risk on CARs, we find marked differences between sales and purchases. Although systematic risk is significant and positive in our purchase samples, it has no effect on CARs in the case of reported insider sales. For both types of transactions, however, the influence of systematic risk is smaller than that of idiosyncratic risk. These findings partly confirm that while both systematic and idiosyncratic risk matter to arbitrageurs, the latter part of total volatility matters more because it is more difficult to hedge.

The short-term risk-free rate, another holding cost item, does not have a 
significant impact on abnormal returns. Along similar lines, we fail to find a statistically significant relationship between CARs and transaction costs. Nevertheless, the regression coefficients of share price, which controls for direct transaction costs such as brokerage commission, have the expected positive sign. The same applies for $V O L U M E$, which picks up indirect transaction costs such as illiquidity, in the case of the purchase and pooled samples.

Our event study analysis has shown that reported insider sales are followed by greater abnormal returns than insider purchases. Our results for the pooled regressions, however, demonstrate that the type of transaction has no direct effect on CARs. As a consequence, our event study results must be driven by other factors such as more extreme past returns associated with sales.

Several other trade-specific variables have a higher explanatory power. The relative size of trades is significant and positive for purchases. This suggests that relatively larger trades trigger larger price reactions. The negative TRADSZ coefficient for sales, however, suggests the contrary. Betzer and Theissen (2007b) find the same unexpected result. Also in accordance with their findings we find no significant impact of reporting delay on CARs. Past returns, on the other hand, are powerful in explaining returns to insider trading. As expected, past stock performance is negatively related to post-event CARs. ${ }^{21}$

Although Seyhun (1986) and Lin and Howe (1990) partially confirm this hypothesis for US data, Fidrmuc et al. (2006) and Betzer and Theissen (2007b) find no evidence for the UK and German markets. Our results also offer no support for the informational hypothesis. Overall, trades by members of the executive board are followed by smaller (absolute) abnormal returns than transactions by members of the supervisory board or the management.

Firm size has the expected effect on abnormal returns following directors' dealings. The negative regression coefficients suggest that CARs shrink as larger companies are considered. Previous studies generally find corresponding evidence (Seyhun 1986, Betzer and Theissen 2007b).

\footnotetext{
${ }^{21}$ Klinge et al. (2005) finds similar results for the German market.
} 
The relationship between the market-to-book value ratio and abnormal returns is significant but has different economic implications for sales and purchases. Value stocks, as measured by a low $M T B V$ ratio, are followed by smaller price movements in the case of sales and larger movements in the case of purchases. The reverse is true for insider trades in high growth or overvalued stocks as measured by a high $M T B V$ ratio. Thus, positive insider trading signals move stock prices less if valuations are already exceedingly high. Market participants seem, however, to be more sensitive to negative signals in high growth stocks as these securities may be associated with greater risk.

The market's response to purchases and sales also differs for companies in financial distress. If a firm's interest coverage ratio is below one, positive purchasing signals are met with caution and abnormal returns are smaller than otherwise. Sales, on the other hand, convey an additional negative signal for a company already in jeopardy. Accordingly, prices react more extremely, and absolute abnormal returns are higher. Except for the pooled models, the regression coefficients for financial distress are significant.

\subsection{Application of Arbitrage Trading Strategy}

The cross-sectional regression analysis confirms the existence of a statistically significant relationship between arbitrage risk and abnormal returns following directors' dealings. On the basis of this result, however, we cannot decide whether signals conveyed by insider trades can be exploited by outside investors. Therefore, we further investigate in this section the relevance of arbitrage risk by constructing a straightforward arbitrage trading strategy based on directors' dealings. By comparing the returns to the trading strategy depending on the underlying level on idiosyncratic risk and by adjusting for transaction costs, we are able to draw conclusions regarding the impact of arbitrage risk on arbitrage opportunities.

We design a zero-investment arbitrage trading strategy as follows: insider purchases (sales) are mimicked by taking a long (short) position in the com- 
pany's stock on the day of the announcement. To hedge the associated fundamental risk of the stock investment, an opposite position in the CDAX index is taken. ${ }^{22}$ After twenty trading days, both positions are liquidated.

We calculate the average returns to the trading strategy using dividend adjusted closing prices, and also employ actual bid/ask quotations in order to account for transaction costs. ${ }^{23}$ It should be noted that several thinly traded stocks exhibit extremely large bid/ask spreads. Once again, for the sake of making our analysis as conservative as possible, we exclude all trades with an bid/ask spread of $10 \%$ or more on the announcement day.

All trades are weighted equally and in addition to total returns we also report separately the average returns to the stock investment and the hedging position. Similar to the arbitrage risk portfolio analysis in section 4.3, average returns are presented for the highest and lowest ranking arbitrage risk quantiles for all trades and purchases and sales only. Results are outlined in table 7.

Disregarding transaction costs, i.e. calculating the returns on the basis of closing prices, the arbitrage trading strategy yields for the pooled sample an average return of $2.41 \%$ for if idiosyncratic risk is high. Also the returns on the purchase-sample as well as on the sales-sample are statistically significant and positive. Furthermore, the return of the high risk arbitrage quantile is in all instances significantly larger than that of the low arbitrage risk quantile. This observation confirms our previous finding that highly idiosyncratic stocks are associated with larger post event returns.

Taking transaction costs in the form of bid/ask spreads into account, we see the spread in returns between high and low arbitrage risk quantiles disappear. Total returns earned by high arbitrage quantiles are not statistically larger than zero. This finding is consistent with the notion that idiosyncratic risk makes

\footnotetext{
${ }^{22}$ Since the CDAX is a broad index index covering all German shares admitted to the Prime and General Standard, there are no investment instruments, and thus not shorting instruments, available to the general public yet. Thus, this can be regarded as a conservative setting for testing arbitrage opportunities.

${ }^{23}$ The bid/ask spread is only one element of direct transaction costs, which also include brokerage commissions and additional costs for short selling. By omitting these additional costs we make our analysis again more conservative.
} 
trading in a stock more costly. As a consequence, market makers increase the bid/ask spread in this stock. Although a clear cut prove of the link between the level of idiosyncratic risk and the bid/ask spread is beyond the scope of this paper, our results show that no excess profits are obtainable from an arbitrage trading strategy based on reported insider trades.

\section{Conclusion}

This paper addresses the question of whether outside investors can profit from reported insider transactions in the German market, since previous studies find large abnormal returns after published directors' dealings. Any trading strategy based upon publicly available information and yielding excess returns would, however, constitute a serious violation of the efficient market hypothesis. We argued that observed post-event price effects in the context of director's dealings may not constitute evidence against the efficient market hypothesis as this effect is not exploitable due to arbitrage risk. Specifically, we hypothesized that large abnormal returns cluster in highly idiosyncratic stocks that are associated with considerable arbitrage risk, prohibiting outsiders to take advantage of the alleged inefficiency.

While our event study analysis reiterated the existence of larger abnormal returns after insider transactions, our arbitrage risk portfolio analysis demonstrated that highly idiosyncratic stocks yield significantly larger post-event abnormal returns than stocks associated with low arbitrage risk. In addition, the speed of price adjustment proves to be much faster if arbitrage risk is low.

The robustness of this positive relationship between CARs and arbitrage risk is verified in the cross-sectional analysis that controls for other factors potentially influencing excess returns. We find that besides arbitrage risk, only very few other factors, such as systematic risk, past returns and the market-to-book ratio, have a significant impact on excess returns.

The implementation of a zero-investment arbitrage trading strategy based 
on directors' dealings also shows that outsiders will hardly be able to profit from reported insider transactions. Just by taking transaction costs in the form of bid/ask spreads into account, and ignoring all other transaction cost, even the large returns of the high arbitrage risk portfolios disappear.

Our results are consistent with the notion that highly idiosyncratic stocks are difficult to hedge, impeding arbitrageurs from engaging in price-correcting trades. This results in a slow price discovery and large post-event excess returns. While arbitrage risk certainly does not eliminate all arbitrage trading, the costs stemming from arbitrage risk reduce the threshold of economic feasibility and thus the quantity and intensity of such trades.

In summary, this paper provides evidence that the German stock market is efficient in the sense that prices reflect publicly available information to the point where the marginal benefit of acting on information exceeds marginal costs.

\section{References}

Admati, A. R. and P. Pfleiderer (1988). A theory of intraday patterns: Volume and price variability. The Review of Financial Studies 1(1), 3-40.

Ali, A., L.-S. Hwang, and M. A. Trombley (2003). Arbitrage risk and the book-to-market anomaly. Journal of Financial Economics 69(2), 355-373.

Ben-David, I. and D. Roulstone (2007, November). Idiosyncratic risk and corporate transactions. Working Paper.

Bernard, V. L. (1987). Cross-sectional dependence and problems in inference in market-based accounting research. Journal of Accounting Research 25(1), 1-48.

Bettis, C., D. Vickrey, and D. W. Vickrey (1997). Mimickers of corporate insiders who make large-volume trades. Financial Analysts Journal 53(5), $57-66$.

Betzer, A. and E. Theissen (2007a). Delays in trade reporting by corporate 
insiders. SSRN eLibrary.

Betzer, A. and E. Theissen (2007b). Insider trading and corporate governance: The case of germany. European Financial Management (Forthcoming).

Bhardwaj, R. K. and L. D. Brooks (1992). The January anomaly: Effects of low share price, transaction costs, and bid-ask bias. The Journal of Finance 47(2), 553-575.

Bhushan, R. (1991). Trading costs, liquidity, and asset holdings. The Review of Financial Studies 4(2), 343-360.

Bhushan, R. (1994). An informational efficiency perspective on the postearnings announcement drift. Journal of Accounting and Economics Volume 18(1), 45-65.

Campbell, C. J. and C. E. Wesley (1993). Measuring security price performance using daily nasdaq returns. Journal of Financial Economics 33(1), 73-92.

Campbell, J. Y., A. W. Lo, A. C. MacKinlay, and R. F. Whitelaw (1997). The Econometrics of Financial Markets, Volume 2. Cambridge Univiversity Press.

Chang, S. and D. Y. Suk (1998). Stock prices and the secondary dissemination of information: The wall street journal's "insider trading spotlight" column. The Financial Review 33(3), 115-128.

Collins, D. W. and W. T. Dent (1984). A comparison of alternative testing methodologies used in capital market research. Journal of Accounting Research 22(1), 38-84.

Corrado, C. J. (1989). A nonparametric test for abnormal security-price performance in event studies. Journal of Financial Economics 23(2), 385395.

Dissanaike, G. and A. Le Fur (2003). On the use of the log car measure in event studies. Journal of Business Finance and Accounting 30(7-8), 
$1165-1170$.

Dymke, B. M. and A. Walter (2006). Insider trading in Germany - do corporate insiders exploit inside information? SSRN eLibrary.

Fama, E. F. (1970). Efficient capital markets: A review of theory and empirical work. The Journal of Finance 25(2), 383-417.

Fidrmuc, J. P., M. Goergen, and L. Renneboog (2006). Insider trading, news releases, and ownership concentration. The Journal of Finance 61(6), $2931-2973$.

Friederich, S., A. Gregory, J. Matatko, and I. Tonks (2002). Short-run returns around the trades of corporate insiders on the London Stock Exchange. European Financial Management 8, 7-30.

Heidorn, H., B. Meyer, and A. Pietrowiak (2004). Performance-Effekte nach Directors Dealings in Deutschland, Italien und den Niederlanden. Hochschule für Bankwirtschaft (HfB) - Working Paper $5 \%$.

Ince, O. S. and R. B. Porter (2006). Individual equity return data from Thomson Datasream: Handel with care! Working Paper.

Jeng, L. A., A. Metrick, and R. Zeckhauser (2003). Estimating the returns to insider trading: A performance-evaluation perspective. Review of Economics and Statistics 85(2), 453-471.

Jensen, M. C. (1978). Some anomalous evidence regarding market efficiency. Journal of Financial Economics 6, 95-101.

Jostarndt, P. (2006). Financial distress, corporate control, and management turnover: A German panel analysis. Munich Business Research, Working Paper.

Klinge, M., U. Seifert, and R. Stehle (2005). Abnormal returns in the vicinity of insider transactions: Unbiased estimates for Germany. Working Paper.

Lin, J.-C. and J. S. Howe (1990, sep). Insider trading in the OTC market. The Journal of Finance 45(4), 1273-1284. 
MacKinlay, A. C. (1997). Event studies in economics and finance. Journal of Economic Literature 35(1), 13-39.

Mashruwala, C., S. Rajgopal, and T. Shevlin (2006). Why is the accrual anomaly not arbitraged away? The role of idiosyncratic risk and transaction costs. Journal of Accounting and Economics 42(1-2), 3-33.

Mendenhall, R. R. (2004). Arbitrage risk and post-earnings-announcement drift. The Journal of Business 77(4), 875-894.

Pontiff, J. (1996). Costly arbitrage: Evidence from closed-end funds. The Quarterly Journal of Economics 111(4), 1135-1151.

Pontiff, J. (2006). Costly arbitrage and the myth of idiosyncratic risk. Journal of Accounting and Economics 42(1-2), 35-52.

Pontiff, J. and M. J. Schill (2003). Arbitrage holding costs and long run returns: Evidence from seasoned equity offerings. Working paper.

Rajan, R. G. and L. Zingales (1995, December). What do we know about capital structure? Some evidence from international data. The Journal of Finance 50(5), 1421-1460.

Rau, M. (2004). Directors' Dealings am deutschen Aktienmarkt. Empirische Analyse meldepflichtiger Wertpapiergeschäfte. Ph. D. thesis, Universität Zürich.

Rozeff, M. and M. Zaman (1998). Overreaction and insider trading: Evidence from growth and value portfolios. The Journal of Finance 53(2), 701-716.

Rozeff, M. S. and M. A. Zaman (1988, January). Market efficiency and insider trading: New evidence. The Journal of Business 61(1), 25-44.

Schultz, P. (1983). Transaction costs and the small firm effect: A comment. Journal of Financial Economics 12(1), 81-88.

Schwert, G. W. Anomalies and market efficiencies. In North-Holland Handbooks of of the Economics of Finance, Chapter 15. 
Seyhun, H. N. (1986). Insiders' profits, costs of trading, and market efficiency. Journal of Financial Economics 16(2), 189-212.

Shleifer, A. and R. W. Vishny (1997). The limits of arbitrage. The Journal of Finance 52(1), 35-55.

Stoll, H. and R. Whaley (1983). Transaction costs and the small firm effect. Journal of Financial Economics 12(1), 57-79.

Stotz, O. (2006). Germany's new insider law: The empirical evidence after the first year. German Economic Review 7(4), 449-462.

Tebroke, H.-J. and A. Wollin (2005). Directors' Dealings, Informationseffizienz and Handelsstrategien. Die Unternehmung 59(1), 31-54.

Tuckman, B. and J.-L. Vila (1992, September). Arbitrage with holding costs: A utility-based approach. The Journal of Finance 47(4), 1283-1302.

Wurgler, J. and E. Zhuravskaya (2002). Does arbitrage flatten demand curves for stocks? The Journal of Business 75(4), 583-608. 
Table 1: Definition of Variables

\begin{tabular}{|c|c|c|}
\hline Variable & Definition & Expected Sign \\
\hline \multicolumn{3}{|c|}{ Holding Cost Variables } \\
\hline $\begin{array}{l}\text { IRISK } \\
\end{array}$ & $\begin{array}{l}\text { Residual variance of a standard market model regression of } \\
\text { stock returns on market returns for the time window from } \\
t_{-261} \text { to } t_{-21} \text {. }\end{array}$ & + \\
\hline IRISKLOG & Logged and centered transformation of IRISK. & + \\
\hline SYSRSK & $\begin{array}{l}\text { Total variance of stock returns for the time window from } \\
t_{-261} \text { to } t_{-21} \text { minus the variance of the residuals (IRISK). }\end{array}$ & + \\
\hline SYSRSKLOG & Logged and centered transformation of SYSRSK. & + \\
\hline $\mathrm{RF}$ & $\begin{array}{l}\text { Short-term risk free interest rate proxied by the } 3 \text {-month } \\
\text { EURIBOR measured on day } t_{-1} \text {. }\end{array}$ & + \\
\hline \multicolumn{3}{|c|}{ Transaction Cost Variables } \\
\hline SPRICE & Average (unadjusted) stock price for $t_{-121}$ to $t_{-21}$. & + \\
\hline VOLUME & $\begin{array}{l}\text { Average stock trading volume in millions of euros } \\
\text { over the days } t_{-121} \text { to } t_{-21} \text {. }\end{array}$ & - \\
\hline \multicolumn{3}{|c|}{ Trade-Specific Variables } \\
\hline INSALE & Indicator variable for sale transactions. & - \\
\hline TRADSZ & $\begin{array}{l}\text { Transaction volume divided by the market value of equity. } \\
\text { The denominator is the mean market capitalization from } \\
t_{-121} \text { to } t_{-21} \text {. }\end{array}$ & + \\
\hline DELAY & Reporting delay between transaction date and reporting day $t_{0}$. & - \\
\hline PASTRET & Market adjusted abnormal return over the days $t_{-81}$ to $t_{-21}$. & - \\
\hline \multicolumn{3}{|c|}{ Insider-Specific Variables } \\
\hline POSEB & $\begin{array}{l}\text { Indicator variable for transactions initiated by members of } \\
\text { the executive board. }\end{array}$ & + \\
\hline POSSB & $\begin{array}{l}\text { Indicator variable for transactions initiated by members of } \\
\text { the supervisory board. }\end{array}$ & + \\
\hline POSMNG & $\begin{array}{l}\text { Indicator variable for transactions initiated by members of } \\
\text { the management, excluding members of the executive board. }\end{array}$ & + \\
\hline \multicolumn{3}{|c|}{ Firm Specific Variables } \\
\hline $\mathrm{MV}$ & $\begin{array}{l}\text { Average market value of equity in millions of euros over the } \\
\text { days } t_{-121} \text { to } t_{-21} \text {. }\end{array}$ & - \\
\hline MVLOG & Logged and centered transformation of MV. & - \\
\hline MTBV & Average market-to-book value over the days $t_{-121}$ to $t_{-21}$. & - \\
\hline DISTRS & $\begin{array}{l}\text { Dummy variable set to one for companies with an } \\
\text { interest coverage ratio below one for two consecutive years } \\
\text { prior to the insider trade. }\end{array}$ & + \\
\hline
\end{tabular}




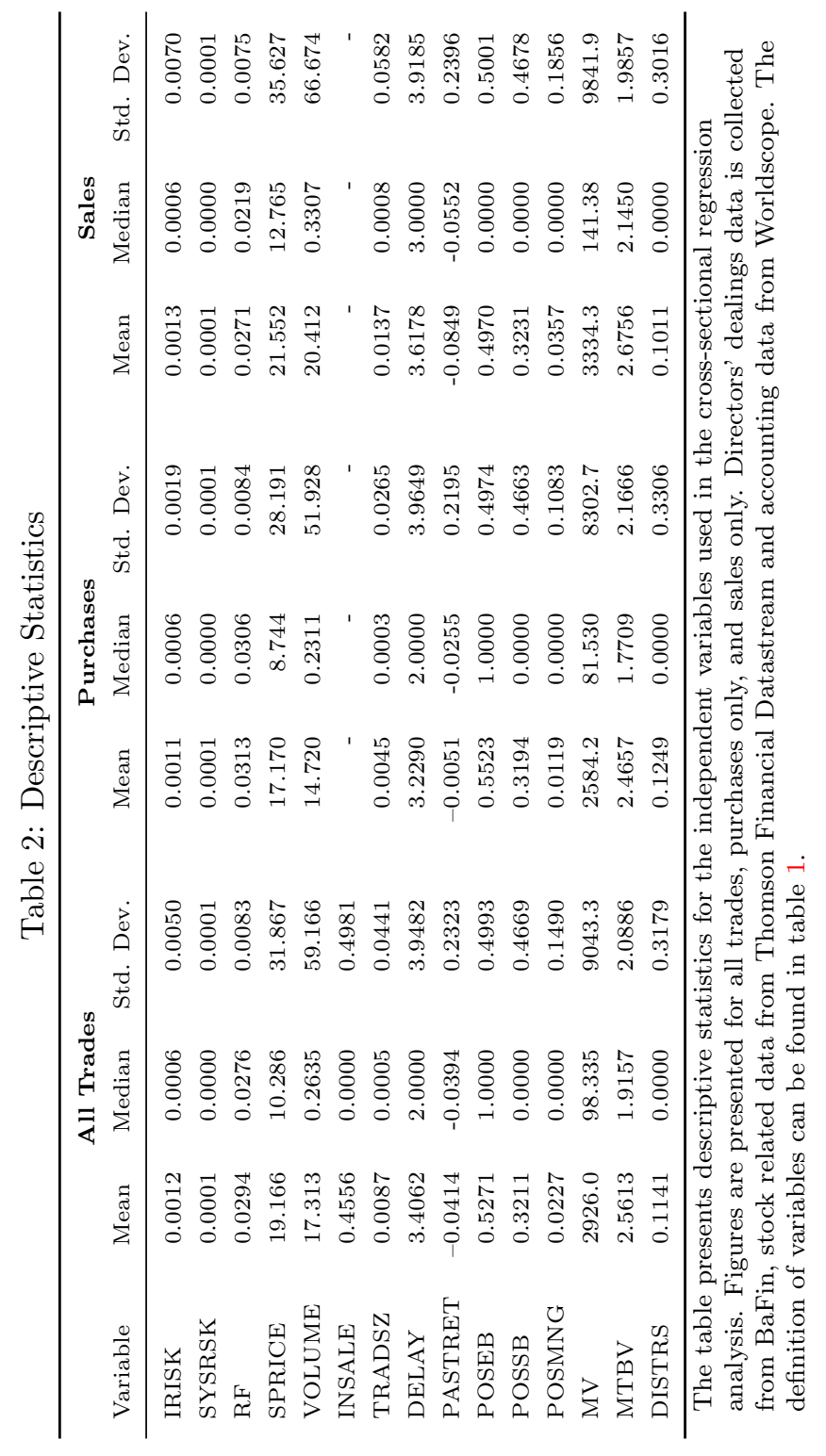




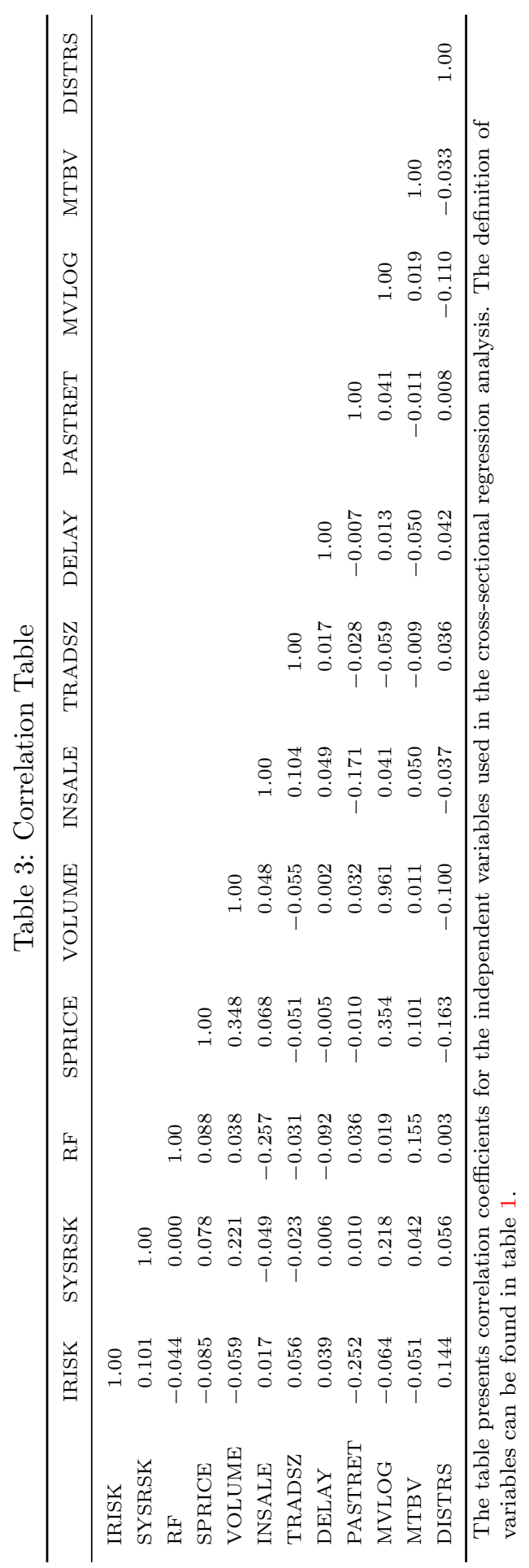




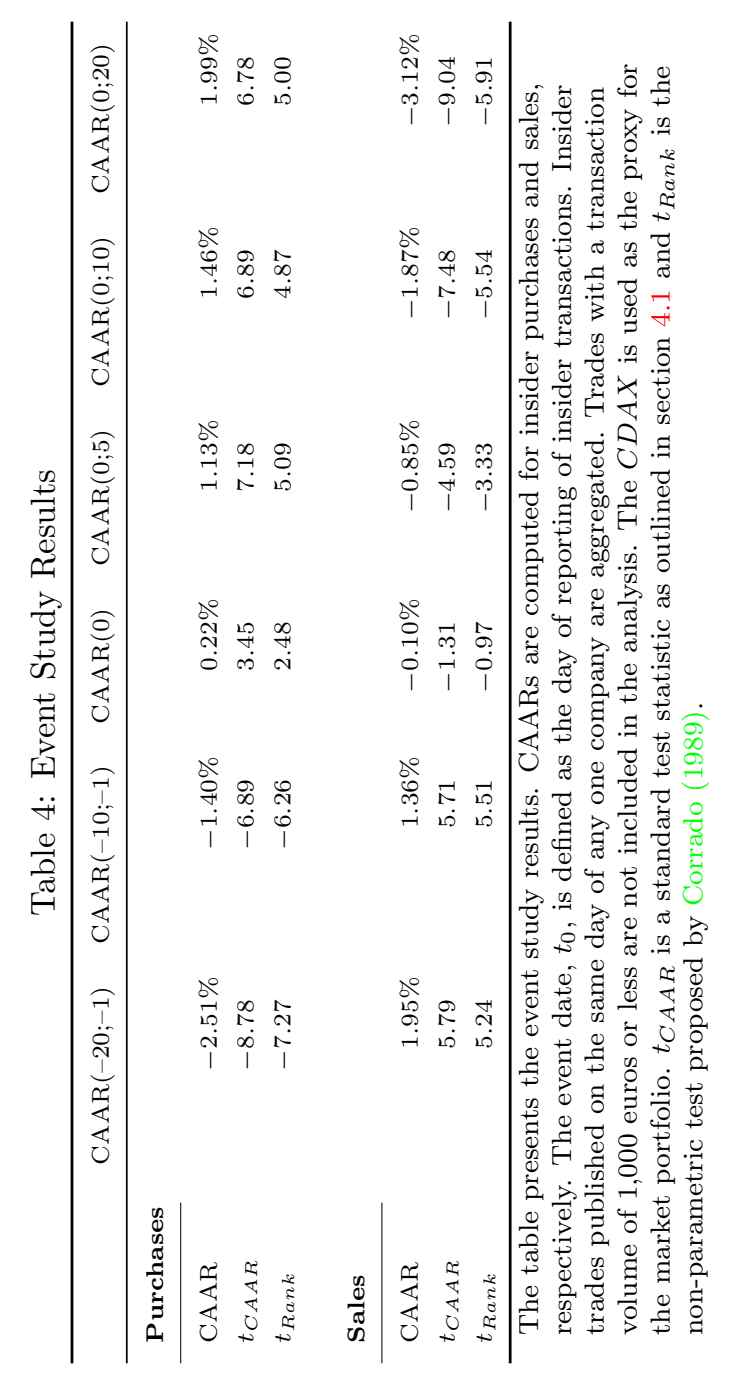




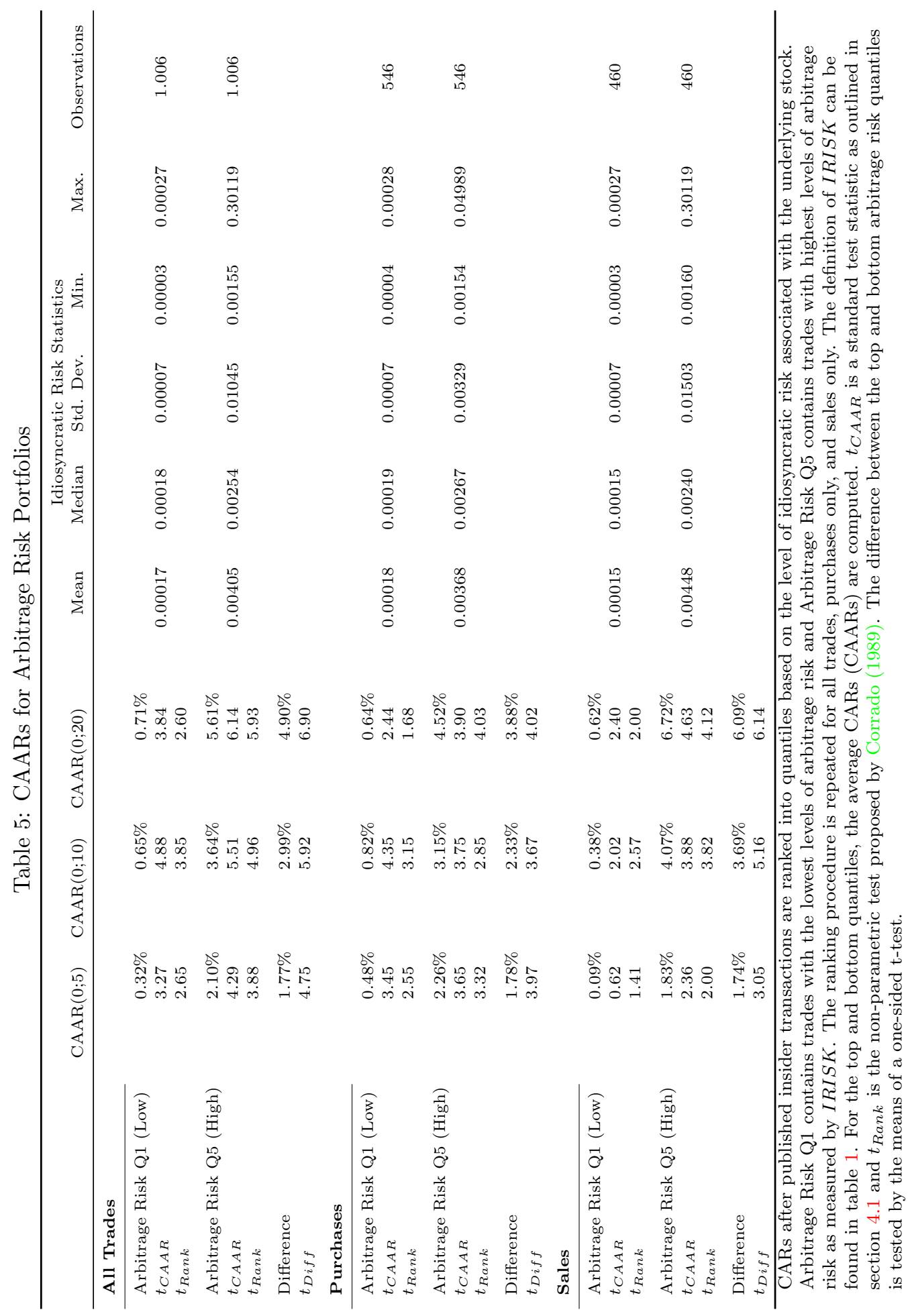


Table 6: Cross-sectional Regression Analysis Results

\begin{tabular}{|c|c|c|c|c|c|c|}
\hline \multirow[t]{2}{*}{ Dependent Variable } & \multicolumn{3}{|c|}{$\operatorname{CAR}(0 ; 10)$} & \multicolumn{3}{|c|}{$\operatorname{CAR}(0 ; 20)$} \\
\hline & Pooled & Purchases & Sales & Pooled & Purchases & Sales \\
\hline Constant & $0.026^{* * *}$ & $0.053^{* * *}$ & -0.009 & $0.053^{* * *}$ & $0.103^{* * *}$ & -0.010 \\
\hline$t$-statistic & 2.69 & 3.95 & -0.69 & 3.97 & 5.65 & -0.54 \\
\hline \multicolumn{7}{|c|}{ Holding Cost Variables } \\
\hline IRISKLOG & $0.011^{* * *}$ & $0.008^{* *}$ & $0.013^{* * *}$ & $0.017^{* * *}$ & $0.013^{* * *}$ & $0.019^{* * *}$ \\
\hline t-statistic & 4.65 & 2.55 & 3.64 & 5.33 & 2.89 & 3.97 \\
\hline SYSRSKLOG & 0.001 & $0.003^{* * *}$ & 0.000 & $0.003^{* *}$ & $0.006^{* * *}$ & -0.001 \\
\hline t-statistic & 1.84 & 2.81 & -0.29 & 2.41 & 4.15 & -0.87 \\
\hline $\mathrm{RF}$ & -0.134 & -0.278 & 0.157 & $-0.610^{* *}$ & $-1.071^{* * *}$ & 0.198 \\
\hline t-statistic & -0.71 & -1.07 & 0.56 & -2.33 & -3.02 & 0.51 \\
\hline \multicolumn{7}{|c|}{ Transaction Cost Variables } \\
\hline SPRICE & 0.000 & 0.000 & 0.000 & 0.000 & 0.000 & 0.000 \\
\hline t-statistic & 0.71 & 0.51 & 0.12 & 0.68 & 0.61 & -0.02 \\
\hline VOLUME & 0.000 & 0.000 & 0.000 & 0.000 & $0.000^{* *}$ & 0.000 \\
\hline t-statistic & 0.60 & 1.27 & -0.19 & 1.41 & 2.27 & 0.13 \\
\hline \multicolumn{7}{|c|}{ Trade-Specific Variables } \\
\hline INSALE & 0.000 & - & - & 0.003 & - & - \\
\hline t-statistic & -0.09 & - & - & 0.77 & - & - \\
\hline TRADSZ & -0.037 & $0.168^{* *}$ & $-0.085^{* *}$ & $-0.100^{* *}$ & 0.158 & $-0.159^{* * *}$ \\
\hline t-statistic & -1.12 & 2.17 & -2.43 & -2.19 & 1.49 & -3.30 \\
\hline DELAY & -0.001 & 0.000 & $-0.001^{* *}$ & $-0.001^{* *}$ & 0.000 & $-0.002^{* * *}$ \\
\hline t-statistic & -1.47 & -0.15 & -2.31 & -1.99 & -0.28 & -3.09 \\
\hline PASTRET & $-0.067^{* * *}$ & $-0.065^{* * *}$ & $-0.075^{* * *}$ & $-0.128^{* * *}$ & $-0.123^{* * *}$ & $-0.148^{* * *}$ \\
\hline t-statistic & -10.60 & -6.90 & -8.30 & -14.73 & -9.51 & -11.91 \\
\hline \multicolumn{7}{|c|}{ Insider-Specific Variables } \\
\hline POSEB & 0.005 & -0.002 & 0.012 & 0.011 & 0.007 & 0.016 \\
\hline$t$-statistic & 1.12 & -0.25 & $2.03^{* *}$ & 1.74 & 0.80 & 1.91 \\
\hline POSSB & 0.000 & -0.001 & 0.002 & 0.007 & $0.018^{*}$ & 0.000 \\
\hline t-statistic & -0.04 & -0.11 & 0.28 & 1.05 & 1.79 & 0.03 \\
\hline POSMNG & 0.010 & 0.026 & 0.009 & 0.003 & 0.043 & -0.005 \\
\hline t-statistic & 0.92 & 1.29 & 0.76 & 0.19 & 1.58 & -0.28 \\
\hline \multicolumn{7}{|c|}{ Company-Specific Variables } \\
\hline MVLOG & -0.001 & -0.004 & 0.002 & -0.002 & -0.008 & 0.003 \\
\hline t-statistic & -0.73 & $-2.17^{* *}$ & 1.17 & -1.24 & $-3.15^{* *}$ & 1.20 \\
\hline MTBV & $-0.002^{* * *}$ & $-0.004^{* * *}$ & 0.001 & $-0.004^{* * *}$ & $-0.009^{* * *}$ & $0.003^{*}$ \\
\hline t-statistic & -2.74 & -4.36 & 1.05 & -4.26 & -7.03 & 1.80 \\
\hline DISTRS & 0.004 & 0.000 & $0.012^{*}$ & 0.001 & -0.011 & 0.024 \\
\hline t-statistic & 0.86 & -0.07 & 1.72 & 0.21 & -1.26 & 2.47 \\
\hline Adjusted $R^{2}$ & $4.05 \%$ & $3.85 \%$ & $5.98 \%$ & $7.19 \%$ & $7.18 \%$ & $10.68 \%$ \\
\hline Average VIF & 1.68 & 1.72 & 1.80 & 1.68 & 1.72 & 1.80 \\
\hline Maximum VIF & 4.06 & 3.80 & 4.61 & 4.06 & 3.80 & 4.61 \\
\hline No. of Observations & 4,796 & 2,611 & 2,185 & 4,796 & 2,611 & 2,185 \\
\hline
\end{tabular}

The table presents results for the cross-sectional (OLS) regressions with CAR(0;10) and $\operatorname{CAR}(0 ; 20)$ as dependent variables. Definitions of the regressors, which include holding cost, transaction cost and trade-, insider- and company-specific variables, can be found in table 1 . The pooled sample consists of all transactions, whereby the CARs on sales are multiplied by -1 . CARs of insider sales are multiplied by minus one. VIF stands for variance inflation factor. $* * *, * *$ and $*$ denote significance at the $1 \%, 5 \%$ and $10 \%$ level respectively. 


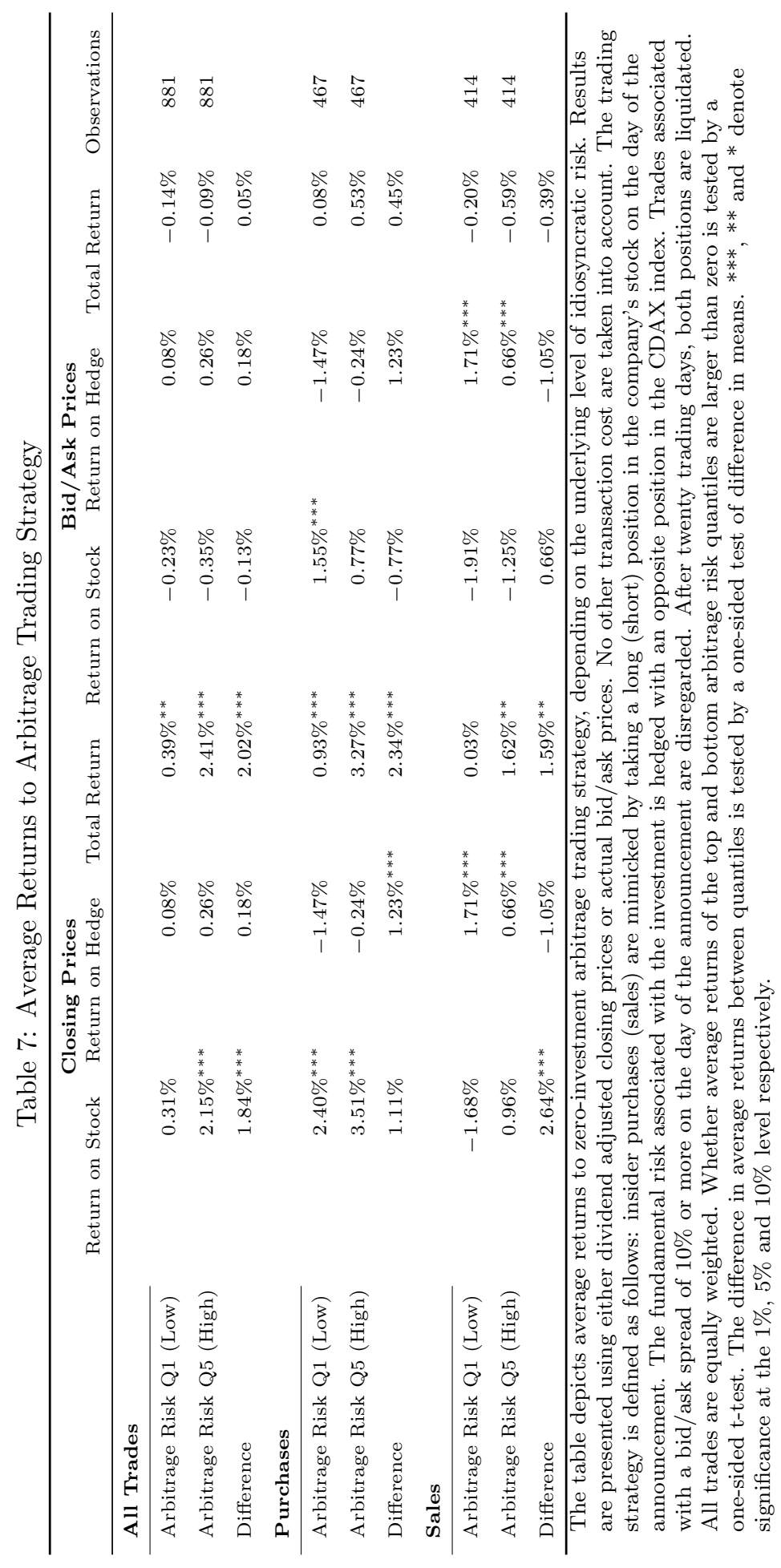




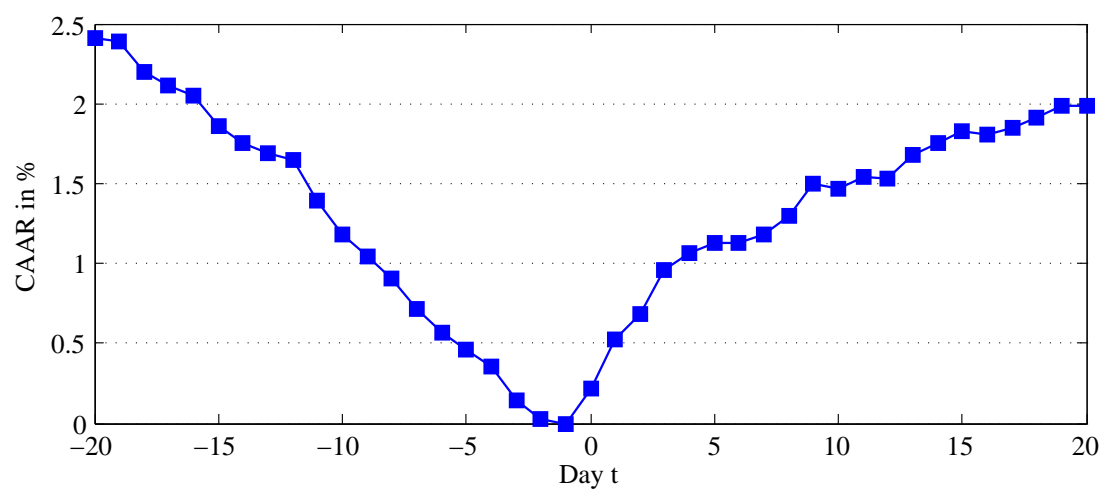

Figure 1: CAARs for Purchase Transactions

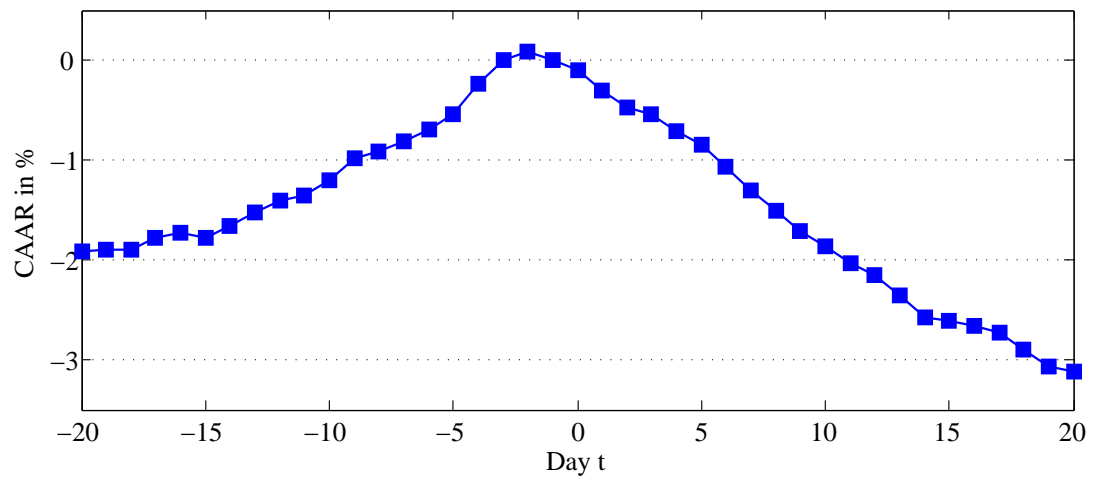

Figure 2: CAARs for Sale Transactions 